\title{
RESPONSE OF WOMEN ON HEALTH CARE SERVICES IN HIMALAYAN HILLS: A STUDY FROM ALMORA DISTRICT OF UTTARAKHAND, INDIA
}

\author{
Dr.Deepak Paliwal \\ Dr.Harish Chandra Joshi \\ Dr.Saroj Paliwal
}

\begin{abstract}
The mountain people, especially the rural women have been the subject of colossal neglect for centuries. In a family, they have different status and role to performed, i.e. mother, daughter, daughter-in-law etc. Their family works are distributed among themselves, according to their position, but the common concern is 'Drudgery'and Health Status which is widely spread in their life. Frequent pregnancies, coupled with poor diet, result in anemia. Illiteracy among women has added to the problem as most of the rural women are subjected to the various traditional beliefs and health practices. Women share abundant responsibilities to perform a wide spectrum of duties both in the home and outside, but their participation is considered as normal by the society. This paper starts with the concept of status of women, health facilities, and moves on to examine the understanding of health seeking behaviorand social dogmas imposed on women and women perception towards various health issues.
\end{abstract}

Keywords- Healthcare services, Women, Himalaya Hills, Health Status, Drudgery 
Dr. Deepak Paliwal \& Dr. Harish Joshi \& Dr. Saroj Paliwal/ Page 61-73

\section{Introduction}

Himalayan hills are characterised by tough geographic and climatic conditions that often impaired with the growth and development of the region. At present, most of the Himalayan hills have poor infrastructure and health facilities, and are characterized by a society with some common malpractices such as caste based misconduct/discrimination, superstitions and intake of excessive alcoholic beverages etc. Even after passage of nearly twenty years since the creation of separate state i.e., State of Uttrakhand, the status of hill people is still not satisfactory in terms of employment, agricultural productivity, health status particularly of women and education. This is the reason, people are forced to migrate to nearby cities, big towns and even to state or national capital regions in order to earn their livelihood and educate their children. The human populace living in villages mostly comprise of those with higher age classes where money-order based economy still in vogue. The per cent forests are continuously on the rise which has, in turn, resulted into more and more dangerous animals moving inside the human habitations. Therefore, man-wildlife conflicts have also increased to great extent. The condition of women is still more miserable. According to an study, it has been estimated that eighty nine and half (89.5) per cent of females in India are engaged in agriculture and industries in rural India with a diversity of roles such as labour works in agricultural fields, housewife, self-cultivators and managers of their homesteads and thus, are invisible backbone of Indian agriculture (Ahmed, 2004; Vineeta Nagarkoti, 2014). 'Drudgery' and 'Health' are still the main concerns of hill women. Higher frequency of pregnancies, coupled with poor diet has resulted in poor health of mothers and in long run its consequences appear in form of malfunctioning of the body. Further, the situation has been worsened by poor women literacy. The women usually remain overloaded with various responsibilities and works inside as well as outside the home. Their household duties and agricultural responsibilities are conceived of as if it is a part of their duties. In addition to this, traditional beliefs and superstitions, poor health and education facilities have also contributed in aggravating the situation. Accordingly with these observations, the present study was planned with the following objectives: 
- to investigate the status of health facilities in the select study area

- to analyse the perception of rural women about traditional and modern health care facilities and available latest technologies

- to assess the traditional health care practices adopted by women in the mountains and to collect knowledge on these practices

- to study the role and impacts of socio-cultural barriers in effective delivery of health services to women

\section{Methodology}

\section{a) Study Area}

The present study was conducted in Almora district of Uttarakhand in India. There are, at present, eleven (11) development blocks (DBs) in the district namely Bhaisyachana, Chokhutia, Dwarahat, Lamgarha, Takula, Bhikiyasaan, Salt, Dholadevi, Hawalbagh, Syalde and Tarikhet. However, for the current study, we have selected Dhauladevi DB for it being the only Educationally Backward Block (EBB) as per MHRD, Government of India (source;http://ssamis.nic.in/blockdetail.do). Map of the study area is shown as Map 1.

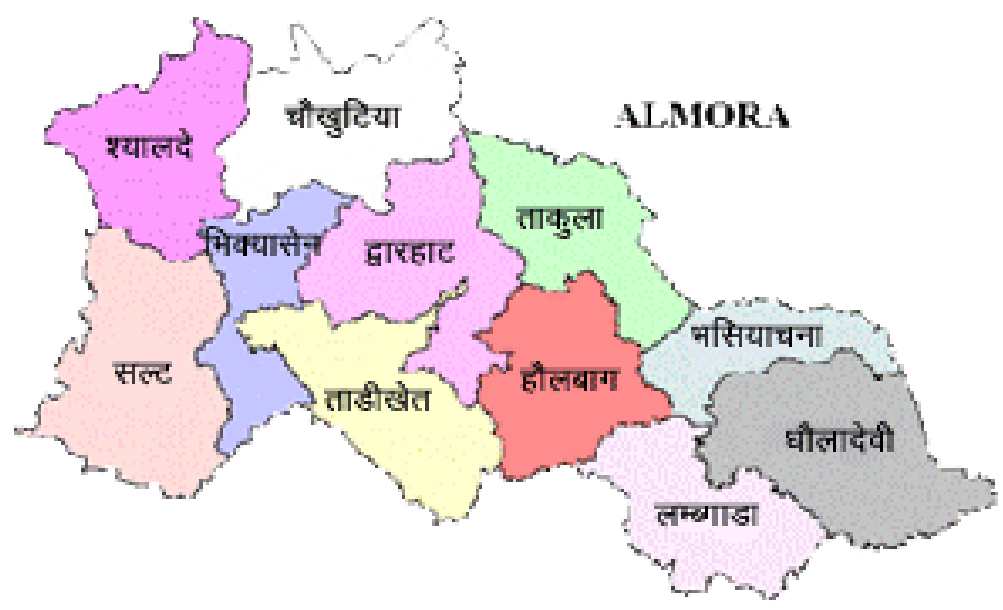




\section{b) Sampling procedure}

Three stage sampling method was followed for the selection of DB, Villages and Respondents. The First stage was to select a DB among the available DBs through purposive sampling, here we have used criteria of being most EBB among the total DBs of the district. Second stage included selection of villages within the selected DB and it was carried out through lottery method.Ten (10) per cent of the total villages in the DB were selected for detailed study. The Third stage of sampling included the selection of households in the select villages and criteria of selecting ten (10) per cent or a maximum of two hundred (200) householdswas followed.

\section{c) Data collection}

Data has been collected from both primary as well secondary sources. Primary data is collected through intensive field work in the select villages. Structured questionnaires were developed for the purpose and personal as well as group interviews were conducted for collecting data. In addition to this, data was also collected through verbal and personal communications. The secondary data was collected from existing records, manuscripts, survey reports and published literature.

\section{d) Analysis of data}

\section{Results and discussion}

i) Selection of Villages: Following the methodology as described above, Dhauladevi DB was selected for the present study. Twenty (20) villages out of 200 villages in the DB were selected through lottery method. In each village ten (10) households/ respondents were selected randomly on the basis of marital status, educational and economic status. This way a total of 200 respondents each representing to one household was selected and information and data collected. The selectvillages are presented in table 1.

\begin{tabular}{||l|l|}
\hline \multicolumn{2}{|l|}{ Table 1. List of select villages } \\
\hline 1 & Agar \\
\hline 2 & Badiyar \\
\hline 3 & BamanSwal \\
\hline 4 & Barakuna \\
\hline 5 & Basoli \\
\hline 6 & Bayali \\
\hline 7 & Bhanoli \\
\hline 8 & Bhargala \\
\hline 9 & Chageti \\
\hline 10 & Chariya \\
\hline 11 & Chil \\
\hline 12 & Dhurka \\
\hline 13 & Dunar \\
\hline 14 & Dungara \\
\hline 15 & Gunaditya \\
\hline 16 & Likoti \\
\hline 17 & Pali \\
\hline 18 & Swari \\
\hline 19 & Taiya \\
\hline 20 & Tarkot \\
\hline
\end{tabular}




\section{ii) Family structure of households}

Family is a basic unit of human society and it is the family where the necessary conditions for the development of human personality are available. The family structures of households studied are presented in Figure 1.

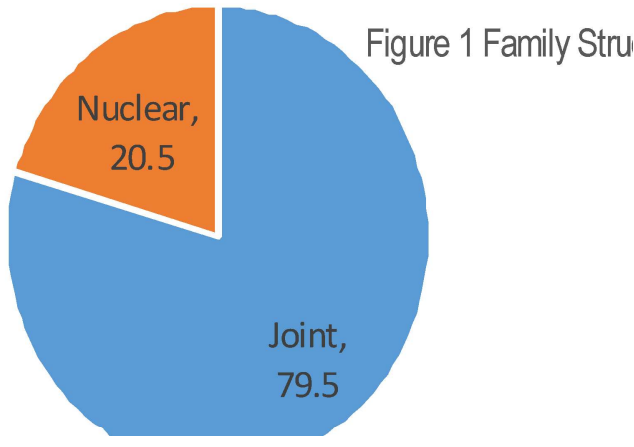
It is evident that majority of the households are still in joint family systems. Although many of the households have separate houses due to restrictions of space in original houses yet they are in joint family system as they share the common properties, share joint responsibilities and they do celebrate festivals as if they are one family. Thus, the concept of joint family system is still alive in the hills. It is generally considered as the foundation of the family and it inculcates among the family members the feeling of joint responsibility for production and consumption. Further, it also affects the life of young generation as their socialization beginsat home in contrary to nuclear families.

\section{iii) Literacy}

According to the census of India (2011), the literacy of District Almora is 73.6 per cent with 91.7 per cent in urban areas and 71.8 per cent in rural areas. The male literacy in the district was higher (89.2 per cent) in comparison to female literacy (60.6 per cent).Among the $11 \mathrm{DBs}$, the highest literacy is of Tarikhet(78 per cent) and lowest is of 
Dr. Deepak Paliwal \& Dr. Harish Joshi \& Dr. Saroj Paliwal/ Page 61-73

Dhauladevi (61.6 per cent). The literacy in rural areas is 88.5 per cent for male and for female 58.4 per cent. The lowest female literacy of was of Dhauladevi Development Block (45.9 per cent). Literacy or status of education is an indicator of development of any society or region or nation. It affects the attitude of humans as well as the way of looking at and understanding any particular social phenomena. The eighth plan also has focus on the universalisation of primary education, promotion of adult literacy and establishment of secondary schools in unreachable areas and, also creation of teaching and research facilities, but all these need adequate planning, policies and societal support. Further, determination for social cause is needed on the part of administrators, government, non-governmental organisations, social workers, and teachers and, above all at household level to make education meaningful and purposeful. Having the lowest female literacy in Dhauladevi DB is one of the important matters of concern as far as health of women is concerned.

\section{iv) Hill women and their workload}

Women in all the villages are more or less engaged in a diversity of activities for extended duration. The diversity of activities she remains engaged upon, is evident from the pie diagram presented in Figure 2. The maximum duration of her engagement was observed in cooking and farm activities. In addition to these activities, she also does other activities such as collection of water, feeding

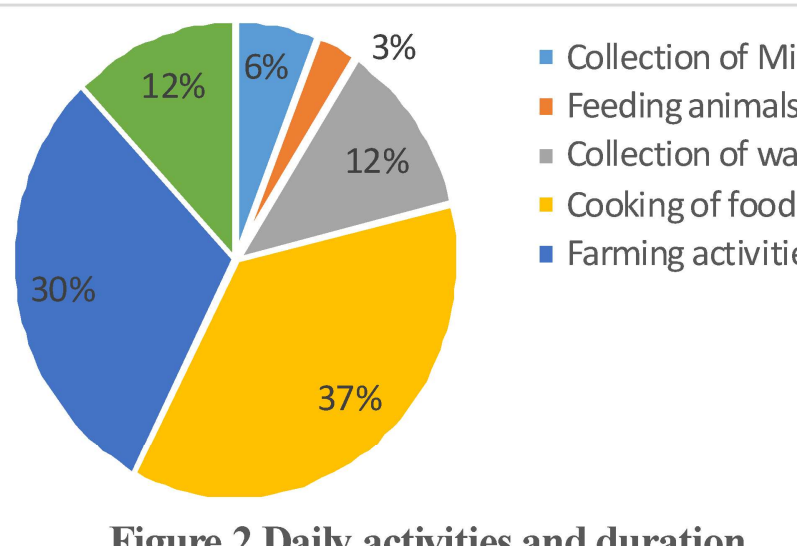
domestic animals, milk collection etc. Due to over engagement in these activities, she has least time for taking good care of herself. 
Dr. Deepak Paliwal \& Dr. Harish Joshi \& Dr. Saroj Paliwal/ Page 61-73

The daily work profile of women in our study area includes cooking, washing homes, cattle rearing, leaning their sheds and undertaking all other household chores including shopping of daily use articles from the nearby markets. All these activities are additional to the conventional farming activities. The ceaseless

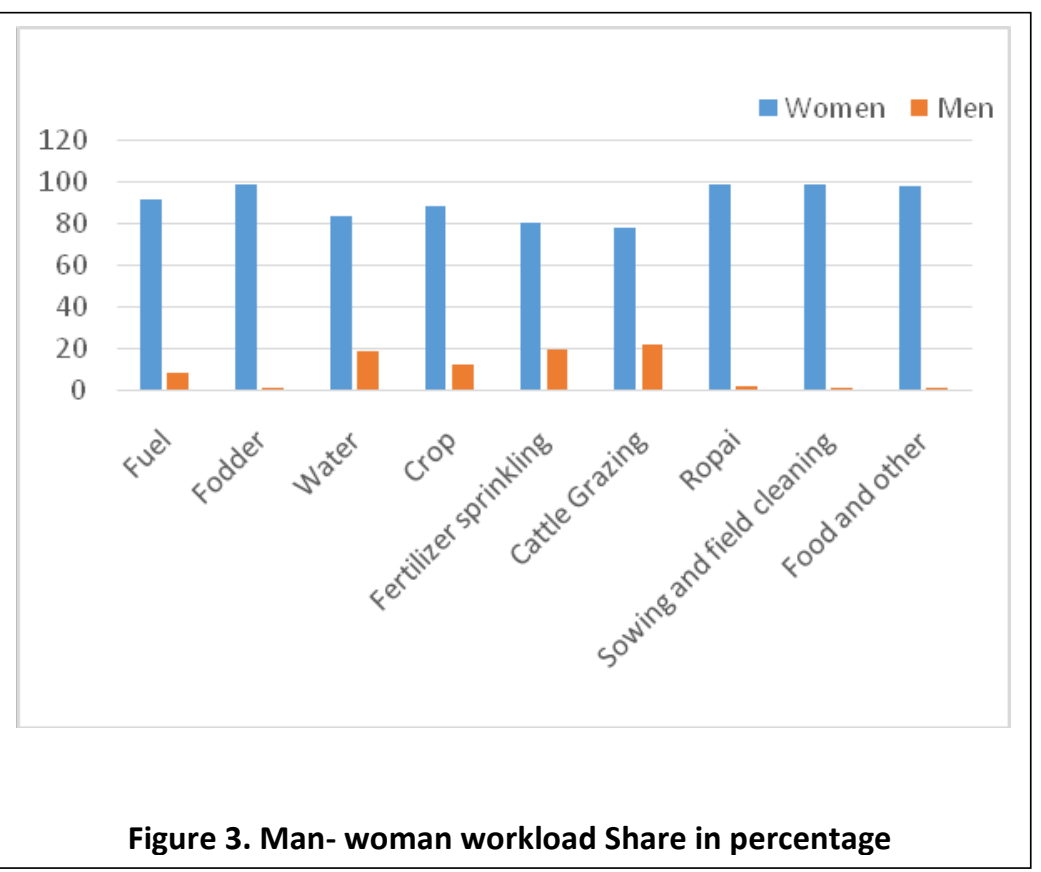
work begins as early as 5 am and she only goes to bed around $10 \mathrm{pm}$. As far as water in villages of Uttarakhand is concerned, a lot of scarcity has been observed. Out of total 16000 villages 8800 villages have been placed as water scarce villages. The districts like Almora, Pauri, Tehri, PithoraGarh and Chamoli are facing drinking water crisis. $72 \%$ women and $14 \%$ children have to bear the responsibility of carrying potable water (UMPR 2010).We have also observed in our study area that water is a big problem and women have to walks $1-2 \mathrm{kms}$ daily in hilly terrain to fetch drinking water.

As far as the workload distribution between men and woman is concerned, it is very unequal and women are mainly overloaded as she is the only person in a household that remains involved in all chores from indoor to outdoor activities. According to a study conducted in 2005, it has been shown that in many instances women's contribution is more than $90 \%$ for example fuel collection $(91.73 \%)$, fodder collection $(99.01 \%)$, paddy transplantation (98.74\%), sowing and cleaning field (98.92\%), foodpreparation and other works (98.20\%) (UPUEA 2005). In majority of the cases, the contribution of men was negligible.

\section{v) Women and their health status in hills}

Health is one of the indicators of development of any society. The existing studies done on the women show that the health of women is comparatively poor than that of men. 
Dr. Deepak Paliwal \& Dr. Harish Joshi \& Dr. Saroj Paliwal/ Page 61-73

Almost one-third of women in Uttarakhand are undernourished as per the weight-forheight index or the body mass index. Nutritional deficiency is more prevalent among illiterate women and women belonging to the household with a low standard of living. Pregnant women get no extra food, and continue doing strenuous work throughout their pregnancies. In India, nearly $3 / 4$ of all births take place at home and 2/3 of all births are not attended by medical personnel. The result of ill health and unsanitary conditions in motherhood meets sometimes death. In Uttarakhand, more than $82 \%$ of deliveries occur at home in rural areas and more than half of these get assistance from dais. Only one of seven births that occur outside a medical facility receives a postpartum check-up within two months of delivery. Facilities available for emergency obstetric care are grossly inadequate in the rural hill area. They have more faith in dais instead of doctor one of the important reason behind this is a low level of awareness and unwillingness of doctor to visit the rural hill area.

Further, there are many social taboos among the women in the hills and many of which are related with women health. One such taboo which directly or indirectly affects the women health is taboos regarding women menstruations. During such periods, women are regarded as untouchable and regarded as impure, and therefore, are not allowed to participate in socio-cultural life, sometimes even kept separately in isolation. It results in long lasting impacts on female's mental and physical health. The menstrual is a biological process which brings about many hormonal changes in female body and many a time women suffer from extreme symptoms such as pain, heavy bleeding, etc. During such times, women needs to be cared well enough so that her health remains in good state, however, due to taboos, it rarely happens. It has been observed in the present study that women themselves promote such taboos and she happily accepts the restrictions imposed on them. Majority of the respondents (57\%) were happy with the restriction whereas only forty three ( $43 \%)$ per cent of respondent felt bad about the restrictions imposed on them during periods. The causes of such happiness was getting time to relaxation as during periods they are not allowed to perform either domestic or other works. Regarding hygiene and care, majority of the respondents $(67.5 \%)$ told that they don't feel any problems as it's a natural process and there is no alternative but to bear it whereas only thirty two (32.5\%) per cent had bad feelings for periods as they 
Dr. Deepak Paliwal \& Dr. Harish Joshi \& Dr. Saroj Paliwal/ Page 61-73

had to suffer from stress and other health issues during such time. Seventy one $(71 \%)$ per cent of the respondents take a rest during menstrual cycle whereas only twenty nice $(29 \%)$ per cent had to take some or other medication in order to cope up with the pain of the cycle. Although menstruation is a natural process, yet demands adequate care and hygiene. Various pogramme and health campaign are being conducted in order to aware the women about the healthy practices to be followed during the menstrual cycle. In the hills, it is observed that women do not discuss about menstruation due to lack education and awareness, and in the absence of resources the hygiene is also compromised. The graph shows that the majority of the women $(69.5 \%)$ used clean clothes during menstruation and minimum number of the respondents $(0.5 \%)$ used pad, etc. Thus, it confirms that women are now more aware of the personal hygiene as they are using clean clothes for the cleanliness. It has also been observed that majority of the respondents $(72 \%)$ per cent discuss their period related issues with their male counterpartwhereas only twenty eight $(28 \%)$ per cent denied it possibly they had the feeling that it is a part of life and they only have to bear the pain.

Menstruation is a natural and biological process, but in the rural areas the women are generally considered as impure during the menstruation period. Rituals in the form of restrictions prevent women to perform and involved in daily activities. The socio-cultural beliefs behind this are based on the concept of 'pollution'. Majority of the respondents $(97.5 \%)$ per cent confess that they are not allowed to visit nearby temples to perform worship, even at home whereas only one per cent of the respondents were of the view that they are even not allowed to cook food and perform other daily activities. The women are relived from such exclusion only after purification after the five days of menstruation. If women unwillingly touch their own child or other, holy water or low cow urine is sprinkled to make them pure. It's clear from the above analysis that there is a need to create awareness among the rural community regarding the misconception which they have towards the menstrual cycle.

\section{vi) Perceptions and Knowledge of the Women towards Health Care Services}

Apart from hygiene and health during menstruation, we tried to understand women's perception and awareness on health care services available in their locality or 
Dr. Deepak Paliwal \& Dr. Harish Joshi \& Dr. Saroj Paliwal/ Page 61-73

elsewhere. Sixty four (64.5) per cent of the respondents accepted that they consult doctor for normal illnesses like fever, headache, etc. whereas only six and half (6.5) per cent accepted that they take homemade medicine for such treatments. Thus, women in the hills have are more aware of their health rights and preferred to take medicine after taking due consultation with trained professionals.

Another important belief regarding women in the rural areas particularly in the hills is that they have least or no knowledge about the treatment and steps to be followed during pregnancy. However, this was only misconception and surprisingly majority of the respondents (i.e. $90.5 \%$ ) had the knowledge about dos and don'ts during pregnancy. It is evident from the fact that majority of them (77\%) had timely vaccination during pregnancy. Though the women have knowledge about the care to be taken during pregnancy and the importance of balanced diet yet they could not follow the same particularly having balanced dietas they are not economically self-sufficient to buy dietary supplements and fruits for them. Thus, it is not awareness but the economically backwardness which poses hindrance in maintaining due health conditions during pregnancy.

Accredited Social Health Activist (ASHA) was created in each village within the identified states to act as a bridge between the rural people and health outlets. Asha is basically a village level female health workers as well as promoter of healthy practices. In the rural areas, Asha as a name indicates a day of hope for the rural women who are unable to visit the doctor frequently due to various reasons. The researcher tries to find out the view of the respondents towards the role and service as provided to them by the ASHA and health worker of their village. The results show that the majority of the respondents $(77.5 \%)$ were fully satisfied with the work and services of the ASHA workers. Further, we also tried to find out the knowledge of the women towards various health facilities available at the village level. It was observed that the majority of the women $(69.5 \%)$ had the least knowhow of the health facilities available at the hospital/Community Health Centres (CHCs)/Primary Health Centres (PHCs). Majority of the respondents $(85 \%)$ preferred to take natural treatment for the primary health needs. 
Thus, it is clear that respondents are still dependent on the natural treatment process for the primary health care with no side effect.

Although there are many PHCs and $\mathrm{CHCs}$ opened in hills yet they do not have adequate facilities at times if serious illnesses. Further, tough topography and long distances to reach to nearest Health Centre usually meet with failure to get timely treatment to the patients. There are instances when pregnant women have given birth in the car or bus while still on the way to hospital. It is observed that opening of health centres is not sufficient but equipping the centre with facilities and adequate staff is still a challenge for the government in Uttarakhand hills. Not only in Hills but in the whole country is a challenge. According to WHO, there should be one doctor for every 1,000 citizens, but this is still far from the goal. As far as availability of staff and doctors in the $\mathrm{PHCs}$ and $\mathrm{CHCs}$ was concerned, majority of the respondents $(79.5 \%)$ endorsed the regular presence of staff in the health centre.

Thus, it may conclude that that respondents are aware of health care and basic hygiene required during various illnesses particularly during pregnancy, yet the lack of health facilities in the health care centres coupled with hill terrain and distances are still a challenge particularly durig some serious or complex illnesses for which facilities are either available in district headquarters or Haldwani or Bareilly which are far away from the study area. Therefore, there is an urgent need to have adequate facilities as per WHO guidelines in hills so that due service to women be rendered at times of necessity with least wastage of time. 


\section{References}

- Black, James.A and Dean J Champion. 1976. Methods and Issues in Social Research .New York: John Willey and Sons.

- Bajpai, S.R. 1997. Methods of Social Survey and Research. Kanpur: KitabGhar.

- Anandhi, S (2007): Women, Work and Abortion: A Case Study from Tamil Nadu. Economic \& Political Weekly. March 24, 2007. P. 1054-1060.

- Ashokkumar and Khan, ME (2010): Health Status of Women in India: Evidences from National Family Health Survey-3 (2005-06) and Future Outlook. Research and Practice in Social Sciences. Vol. 6. No.2. August 2010. P. 1-21.

- Bano, Bushara and Jha, Rajiv Kumar (2012): Organizational Role Stress Among Public and Private Sector Employees: A Comparative Study. The Lahore Journal of Business. Vol. 1. No. 1. Summer 2012. P. 23-36.

- Dalmia, Aaradhana J (2012): Strong Women, Weak Bodies, Muted Voices Women Construction Workers in Delhi. Economic \& Political Weekly. Vol. 47. No. 26 \& 27. June 30, 2012. P. 249-256.

- Holeyannavar, PG and Itagi, SK (2011): Relationship Between Stress, Health Status and Emotional Competence of Primary School Teachers and Housewives. Humanity and Social Sciences Journal. Vol. 6. No. 1. 2011. P. 59-65.

- Jamwal, Renu and Gupta, Deepti (2010): Work Participation of Females and Emerging Labour Laws in India. Asia-Pacific Journal of Social Sciences. Vol. 2. No. 1. JanuaryJune 2010. P. 161-172.

- Sharma, RK and Dhawan, Saroj (1986): Health Problems of Rural Women. Health and Population: Perspectives and Issues. Vol. 9. No. 1. 1986. P. 18-25.

- Ajithkumar, N and Radhadevi, D (2010): Health of Women in Kerala: Current Status and Emerging Issues. Working Paper No. 23. Kochi: Centre for Socio-economic and Environment

Studies, January 2010.

\section{Dr.Deepak Paliwal}

\section{Joint Director, Dr.R.S.Tolia Uttarakhand Academy of Administration, Ardwell Camp,Mallital,Nainital, Uttarakhand}


Dr. Deepak Paliwal \& Dr. Harish Joshi \& Dr. Saroj Paliwal/ Page 61-73

\section{Email-dipaksociology@gmail.com}

\&

\section{Dr.Harish Chandra Joshi}

Assistant Professor (Forestry), School of earth \& Environment Science, Uttarakhand Open University, Haldwani

email-hcjoshi@uou.ac.in

$\&$

Dr.Saroj Paliwal

Reserach Fellow (Sociology of Culture), Ministry of Culture, Government of India

email-sarojpapnai83@gmail.com 